\section{Response of Selected Garden Roses to Drought Stress}

\author{
Xiaoya Cai and Terri Starman ${ }^{1}$ \\ Department of Horticultural Science, Texas A\&M University, 2133 TAMU, \\ College Station, TX 77843
}

\section{Genhua Niu}

Department of Horticultural Science, Texas AgriLife Research and Extension Center, Texas A\&M System, 1380 A\&M Circle, El Paso, TX 79927

\section{Charles Hall and Leonardo Lombardini}

Department of Horticultural Science, Texas A\&M University, 2133 TAMU, College Station, TX 77843

Additional index words. drought tolerance, gas exchanges, water relations, water use efficiency

\begin{abstract}
A greenhouse study was conducted to evaluate the response of four garden roses (Rosa $\times$ hybrid L.), 'RADrazz', 'Belinda's Dream', 'Old Blush', and 'Marie Pavie', to drought stress. Plants grown in containers were subjected to two watering treatments, well-irrigated [water as needed: $\approx 35 \%$ substrate moisture content (SMC) at re-watering] and cyclic drought stress (withholding irrigation until plants exhibit incipient wilting: $\approx 10 \% \mathrm{SMC}$, then re-watering to field capacity for subsequent dry down). Shoot growth and flower number were reduced in the drought treatment compared with the wellirrigated plants in all cultivars with least reduction in 'RADrazz'. Drought stress reduced root growth in 'Belinda's Dream' and 'Marie Pavie', whereas there was no difference in root growth in 'RADrazz' and 'Old Blush'. Decreased SMC induced reduction in net photosynthetic rate $\left(\mathrm{P}_{n}\right)$, stomatal conductance $\left(g_{S}\right)$, transpiration rate $(E)$, and midday leaf water potential $(\psi)$. Leaf water use efficiency (WUE) increased as SMC decreased in all cultivars. However, the relationship between these physiological parameters and SMC differed among the cultivars. At SMC between $10 \%$ and $20 \%$, 'RADrazz' had higher $P_{n}, g_{S}$, E, and WUE compared with the other three cultivars. Therefore, 'RADrazz' was the most drought-tolerant during container production among the cultivars investigated. With lower gas exchange rates and greater reduction in flower number at low SMC, 'Marie Pavie' was less drought-tolerant compared with the other three cultivars.
\end{abstract}

Water shortage and poor water quality are critical challenges to gardening and landscaping in many regions of the world. Population growth and increased urbanization have increased competition for fresh water among agriculture, industry, and municipal water users (Lea-Cox and Ross, 2001). Therefore, water conservation and the improvement of irrigation efficiency are important in landscape water management (Nicolas et al., 2008; Niu et al., 2006). With watering restrictions, the effect of drought stress is exacerbated on plant establishment and survival, and selection of drought-tolerant plants becomes increasingly important for the development of sustainable landscapes.

Roses (Rosa $\times$ hybrid L.) are some of the most common garden plants in the world, and garden roses are one of the most popular and widely cultivated flowering plants. Moreover, some are valued for having ornamental fruit, and they can be used as hedges, screens,

Received for publication 10 Apr. 2012. Accepted for publication 30 May 2012.

${ }^{1}$ To whom reprint requests should be addressed; e-mail tstarman@tamu.edu. apical parts of leaves and whole leaves (Blum, 1996). Plants with a larger leaf area have a higher ratio of transpiration to evaporation, which results in higher WUE (Kingeman et al., 2005). In a study of five low-maintenance rose cultivars under water stress conditions, 'Pink Meidiland' had the smallest leaf surface area, whereas 'Ferdy' had the largest root-to-shoot ratio and lowest leaf area ratio, which may contribute to larger leaf water reserve and moisture uptake for better adaptation to drought conditions (Henderson et al., 1991).

In a study by Niu and Rodriguez (2009), Rosa $\times$ odorata, which was considered to be the least drought-tolerant cultivar, had lower leaf $\mathrm{P}_{\mathrm{n}}, \mathrm{E}$, and $g_{\mathrm{S}}$ than the other three cultivars investigated under SMC between $10 \%$ and $20 \%$. Similar results were found with oleander (Nerium oleander L.) wherein drought-tolerant clones under water deficit conditions had greater gas exchange rates than those less tolerant to drought (Niu et al., 2008). In a study on two miniature roses ('Poulhappy Charming Parade' and 'Poulbian Bianca Parade'), $g_{\mathrm{S}}$ and $\mathrm{P}_{\mathrm{n}}$ in drought-treated plants were restored to rates comparable to well-irrigated plants after re-watering, although $\mathrm{E}, g_{\mathrm{S}}$, and $\mathrm{P}_{\mathrm{n}}$ were reduced under drought-stressed conditions (Williams et al., 1999). They also concluded that droughtstressed miniature roses produced more dry matter per volume of water consumed compared with well-irrigated plants, which might result in improvement of plant drought tolerance by using water more efficiently. Egilla et al. (2005) found that relative water content, E, and $g_{\mathrm{S}}$ were decreased under drought-stressed conditions in Chinese hibiscus (Hibiscus rosa-sinensis L.). In another study on ponderosa pine (Pinus ponderosa Dougl.) and big sagebrush (Artemisia tridentata Nutt.), plants grown under drought had greater WUE than those under wellirrigated conditions (DeLucia and Heckathorn, 1989).

Knowing how garden roses respond to stress will provide useful information that breeders can use in developing adaptable rose cultivars and lead to a better understanding of why certain cultivars withstand unfavorable environmental conditions better than others. Earth-Kind ${ }^{\circledR}$ is a special designation given to select rose cultivars by the Texas AgriLife Extension Service through the Earth-Kind landscaping program. It is based on the results of extensive research and field trials and is awarded only to those roses demonstrating superior pest tolerance combined with outstanding landscape performance (Aggie Horticulture, 2012). Our objectives were to investigate the relative drought tolerance in three Earth-Kind ${ }^{\circledR}$ garden roses ('Old Blush', 'RADrazz', and 'Belinda's Dream') and one ('Marie Pavie') observed to withstand heat and drought stresses in southern landscapes. We evaluated the response of growth, water relations, and gas exchange rates of these rose cultivars to drought stress. We postulated that greenhouse studies could provide insight about physiology of plants under 
drought-stressed conditions, which is a basis for species selection in dry landscapes.

\section{Materials and Methods}

Plant materials and culture. A total of 200 stem cuttings of garden roses, 'Belinda's Dream', 'RADrazz', 'Marie Pavie', and 'Old Blush', were collected from stock plants and rooted in a mist bed. Rooted cuttings were transplanted to $10-\mathrm{cm}$ pots filled with Sunshine LC1 (Canadian sphagnum peatmoss, perlite, starter fertilizer charger, dolomitic limestone, and a long-lasting wetting agent) (Bellevue, WA) on 2 Oct. 2010 in an unshaded glass greenhouse at College Station, TX. Plants were transplanted to $11.4-\mathrm{L}$ pots with the substrate of Sunshine Professional Growing Mix 4 (Canadian sphagnum peatmoss, perlite, starter fertilizer charge, a controlled-release fertilizer, and dolomite limestone) on 7 Dec. 2010. During this establishment stage, plants were pruned once a week to remove flower buds and improve plant shape, and they were irrigated as needed using a nutrient solution containing $300 \mathrm{mg} \cdot \mathrm{L}^{-1} 15 \mathrm{~N}-1.1 \mathrm{P}-6.2 \mathrm{~K}$ and reverse osmosis water. The plants were periodically watered with $5.15 \mathrm{~g} \cdot \mathrm{L}^{-1}$ Sequestrene 138 (6\% iron chelate) (Becker Underwood, Inc., Ames, IA) to prevent iron deficiency.

Although the cultivars used for the study are relatively pest-free in the landscape, in this greenhouse study, plant foliage was washed with soapy water periodically to control spider mites. Effort was also made to control powdery mildew disease by applying Daconil Ultrex (chlorothalonil) (Syngenta Crop Protection, Inc., Greensboro, NC) fungicide weekly starting mid-Feb. 2011. Greenhouse temperatures were controlled by a pad-and-fan cooling system during the summer and by a natural gas heating system during the winter. The average temperature in the greenhouse was $22.8^{\circ} \mathrm{C}$ day/ $18.1{ }^{\circ} \mathrm{C}$ night, which was measured and logged by temperature sensors (HOBOs; Onset Computer Corp., Bourne, MA). The average daily light integral and the average relative humidity, measured using RH/PAR sensors (Watchdogs; Spectrum Technologies), were $19.3 \mu \mathrm{mol} \cdot \mathrm{m}^{-2} \cdot \mathrm{d}^{-1}$ and $55.6 \%$, respectively (Fig. 1).

Drought treatment. Uniform plants of each cultivar were selected and divided into two irrigation treatment groups: well-irrigated and cyclic drought stress. Each treatment contained 10 plants per cultivar. The plants in each cultivar were pruned to uniform heights and rotated around the bench weekly to reduce variability. Irrigation treatment was initiated on $8 \mathrm{Feb}$. and ended on 31 Mar. 2011. At the beginning of the experiment, an extra plant was dried to wilting point, and SMC was then determined. Cyclic drought stress was imposed by withholding irrigation until the incipient wilting occurred $(\approx 10 \%$ $\mathrm{SMC}$ ). Plants were then re-watered to field capacity and allowed to dry to $10 \%$ SMC again. During that period $(\approx 7 \mathrm{~d})$, plant gas exchange and midday leaf $\psi$ were measured
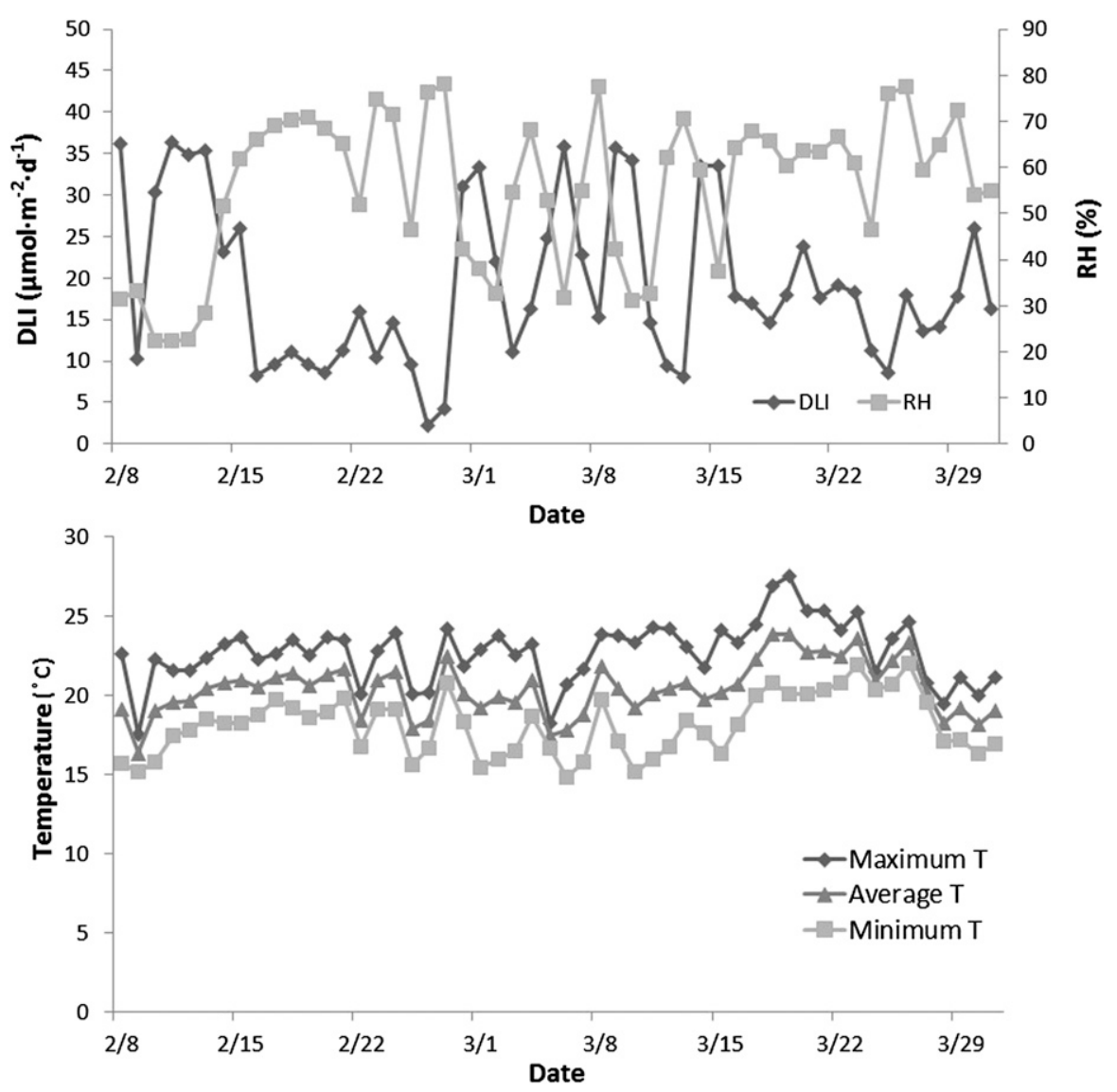

Fig. 1. Variation of temperature (T) (maximum, minimum, and average), daily light integral (DLI), and relative humidity $(\mathrm{RH})$ in the greenhouse during the experiment period.

Table 1. Flower number, shoot and root dry weight (DW) of four rose (Rosa $\times$ hybrid L.) cultivars, Old Blush, RADrazz, Belinda's Dream, and Marie Pavie, grown under well-irrigated cycle or subjected to cyclic drought stress for 7 weeks $(n=10)$.

\begin{tabular}{llccc}
\hline Cultivar & Irrigation treatment (SMC) & Flower number & Shoot DW(g) & Root DW (g) \\
\hline Old Blush & Well-irrigated (35\% to 40\%) & $41.0 \mathrm{a}^{\mathrm{z}}$ & $68.5 \mathrm{a}$ & $1.8 \mathrm{a}$ \\
& Drought (10\% to 40\%) & $25.8 \mathrm{~b}$ & $46.2 \mathrm{~b}$ & $1.4 \mathrm{a}$ \\
RADrazz & Well-irrigated (35\% to 40\%) & $18.9 \mathrm{a}$ & $48.2 \mathrm{a}$ & $2.2 \mathrm{a}$ \\
& Drought (10\% to 40\%) & $11.2 \mathrm{~b}$ & $38.1 \mathrm{~b}$ & $1.8 \mathrm{a}$ \\
\multirow{3}{*}{ Belinda's Dream } & Well-irrigated (35\% to 40\%) & $6.6 \mathrm{a}$ & $38.8 \mathrm{a}$ & $1.2 \mathrm{a}$ \\
& Drought (10\% to 40\%) & $3.5 \mathrm{~b}$ & $24.9 \mathrm{~b}$ & $0.7 \mathrm{~b}$ \\
Marie Pavie & Well-irrigated (35\% to 40\%) & $30.8 \mathrm{a}$ & $42.2 \mathrm{a}$ & $1.4 \mathrm{a}$ \\
& Drought (10\% to 40\%) & $12.2 \mathrm{~b}$ & $27.1 \mathrm{~b}$ & $0.8 \mathrm{~b}$ \\
\hline
\end{tabular}

${ }^{2}$ Values in a column followed by different letters differ significantly at $P=0.05$ for the same cultivar.

every other day. The regime was repeated three more times. The control plants were well-irrigated (water as needed to keep minimal SMC $\approx 35 \%$ ) throughout the experiment. The irrigation frequency for drought-treated plants ranged from every other week to once per week varying with plant size and greenhouse environmental conditions. Well-irrigated plants (control) were watered twice or three times per week. The same nutrient solution was applied to all plants at each irrigation event.

Measurements. Midday $\psi$ was measured on young, fully expanded leaves using a pressure bomb (Soil Moisture Equipment Corp., Santa Barbara, CA) every other day during each dry-down cycle. Instantaneous leaf gas exchange parameters $\left(\mathrm{P}_{\mathrm{n}}, g_{\mathrm{S}}\right.$, and E) were measured on six plants for each cultivar every other day during each dry-down cycle. Between 1000 and $1200 \mathrm{HR}$, a young, fully expanded leaflet was put into the leaf chamber (cuvette) of a portable infrared gas exchange analyzer (LI-6400XT; LI-COR Inc., Lincoln, NE) with cuvette conditions set at $25{ }^{\circ} \mathrm{C}, 1000 \mu \mathrm{mol} \cdot \mathrm{m}^{-2} \cdot \mathrm{s}^{-1}$ photosynthetic photon flux, and $400 \mu \mathrm{mol} \cdot \mathrm{mol}^{-1} \mathrm{CO}_{2}$. Data were recorded when the environmental conditions and gas exchange parameters in the cuvette became stable. Instantaneous WUE was determined as $\mathrm{P}_{\mathrm{n}} / \mathrm{E}$. Substrate moisture content was measured with a calibrated theta probe (Type HH2; Delta-T Devices, Cambridge, U.K.). Flower number was recorded at the end of the experiment and plant growth was determined by harvesting plant shoots and roots. Plants roots were harvested by shaking out and washing away the soil 
media in roots. Dry weight (DW) of shoots and roots was measured after being ovendried at $80{ }^{\circ} \mathrm{C}$ for $72 \mathrm{~h}$.

Experimental design and statistical analysis. The experiment used a split-plot design with irrigation treatment as the main plot and four cultivars as the subplot with 10 replications per treatment for each cultivar. A two-way analysis of variance procedure was used to test the effects of drought stress and cultivar on plant growth. Means were separated in two treatments of each cultivar by least significant difference $t$ test when there was an interaction between treatment and cultivars. Linear or quadratic regression analyses were performed to determine the nature and significance of association between $\mathrm{P}_{\mathrm{n}}, \mathrm{E}, g_{\mathrm{S}}, \psi$, and WUE and SMC during the four dry-down cycles, which were selected based on the significance of quadratic correlation. When the quadratic correlation was not significant, a linear regression was chosen. General linear model procedure analyses were performed to determine the differences of two lines by comparing the slope and intercepts. All statistical analyses were performed using SAS (Version 9.1.3; SAS Institute, Cary, NC) to determine treatment differences at the 0.05 level of significance.

\section{Results and Discussion}

Growth. There were interactions between irrigation treatment and rose cultivar for all growth parameters. Compared with wellirrigated plants, flower number of 'Old Blush', 'RADrazz', 'Belinda's Dream', and 'Marie Pavie was reduced by $37 \%, 41 \%$, $47 \%$, and $60 \%$, respectively, whereas shoot DW of these four cultivars was reduced by $33 \%, 21 \%, 36 \%$, and $36 \%$, respectively, under drought stress conditions (Table 1). Drought stress did not affect the root DW of 'Old Blush' and 'RADrazz', whereas root DW of 'Belinda's Dream' and 'Marie Pavie' was reduced by $42 \%$ and $43 \%$, respectively (Table 1). No difference was found in rootto-shoot ratio between the drought and wellirrigated plants in any cultivar.

Drought stress was reported to reduce plant growth in many studies (Eakes et al.,
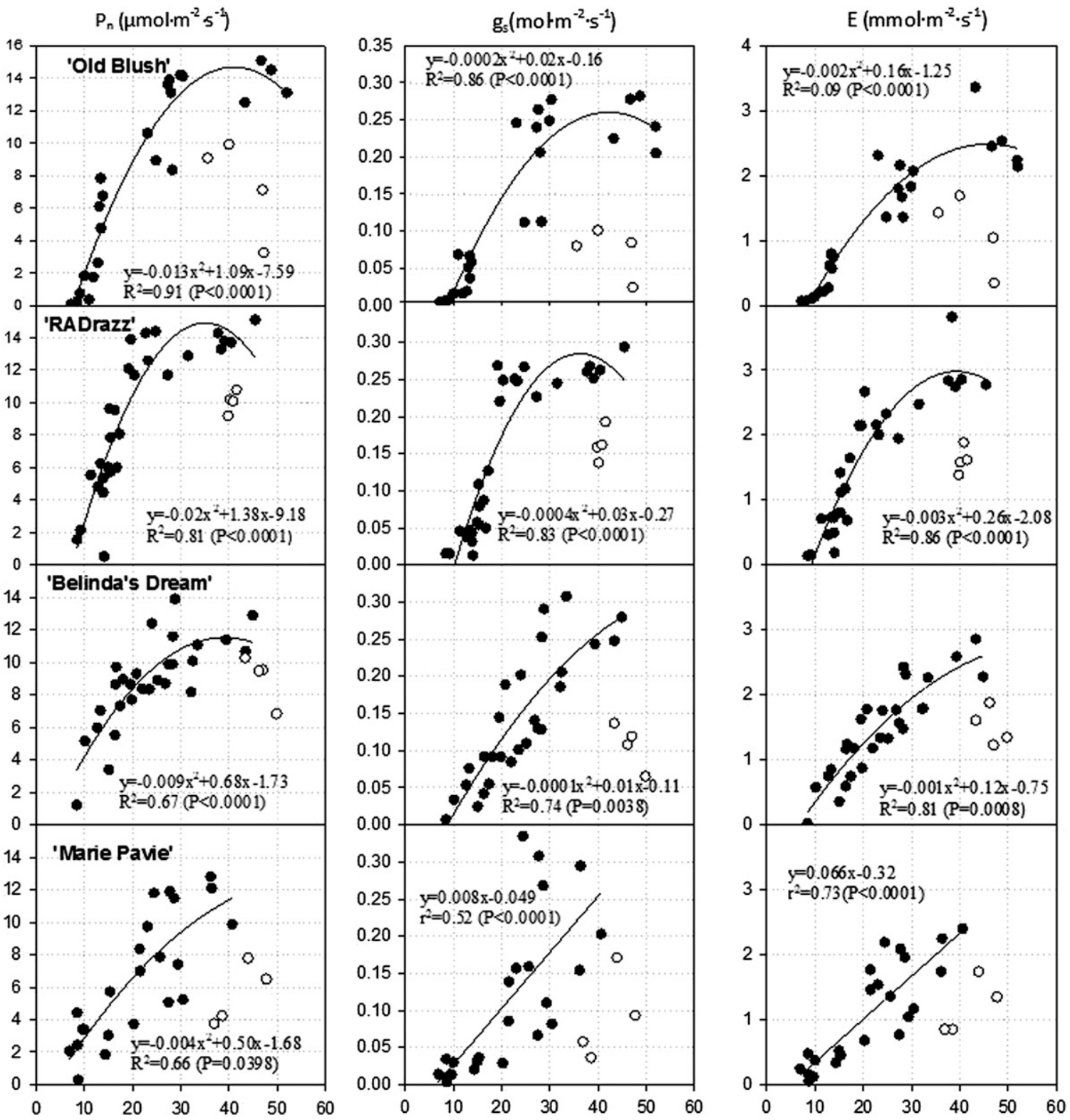

\section{Substrate Moisture Content (\%)}

Fig. 2. Relationship between leaf net photosynthetic rate $\left(\mathrm{P}_{\mathrm{n}}\right)$, stomatal conductance $\left(g_{\mathrm{S}}\right)$, transpiration rate $(\mathrm{E})$, and the substrate moisture content (SMC) for four rose (Rosa $\times$ hybrid L.) cultivars, Old Blush, RADrazz, Belinda's Dream, and Marie Pavie, measured during dry down. The open symbols represent data measured on the second day of the dry down when plants were not fully recovered from the previous drought stress. The regression analysis excluded these data. 
1991; Niu et al., 2008; Niu and Rodriguez, 2009). In oleander, shoot growth, leaf area, and specific leaf mass were reduced under water deficit conditions, whereas root DW was unaffected by drought treatment (Niu et al., 2008). Maintaining root growth under drought stress may aid in water uptake; therefore, plants have better adaptation to stressed environment. Additionally, root-toshoot ratio was higher under drought stress, which resulted from a relatively larger decrease in shoot growth than in root growth (Niu et al., 2008). Increased root-to-shoot ratio is a characteristic of many droughttolerant species, which indicates a greater carbon allocation to a larger root system for moisture uptake under water stress conditions (Henderson et al., 1991). Reduced shoot DW and total leaf area were found under moisture stress conditions in bonfire salvia (Salvia splendens F. Sellow), which was the result of loss of turgor during dry-down cycles (Eakes et al., 1991). Turgor loss has been reported to cause reductions in cell division and elongation as well as essential metabolic processes required for plant growth and development (Hsiao, 1973). In bigtooth maples (Acer grandidentatum Nutt.), drought-stressed plants were less efficient in accumulating dry matter than well-irrigated plants (Bsoul et al., 2006). The lower growth reduction observed in 'RADrazz' under drought stress showed its better adaptation to water deficit conditions compared with the other three cultivars (Table 1). Greater reductions in flower number and leaf size were observed in 'Marie Pavie' under drought stress, which presented as minimized water loss through drought avoidance. In these four cultivars, no difference was found in root-to-shoot ratio in drought and well-irrigated plants.

Gas exchange. During the dry down, as SMC decreased, $\mathrm{P}_{\mathrm{n}}, g_{\mathrm{S}}$, and $\mathrm{E}$ for 'Old Blush', 'RADrazz', and 'Belinda's Dream' and $\mathrm{P}_{\mathrm{n}}$ for 'Marie Pavie' decreased quadratically, whereas $g_{\mathrm{S}}$ and E for 'Marie Pavie' decreased linearly (Fig. 2). In the range of $20 \%$ to $40 \%$ SMC, 'Old Blush' and 'RADrazz' generally had greater $\mathrm{P}_{\mathrm{n}}, g_{\mathrm{S}}$, and E compared with those of 'Belinda's Dream' and 'Marie Pavie' (Fig. 2). At SMC of $10 \%$ to $20 \%$, 'Marie Pavie' generally had lower $\mathrm{P}_{\mathrm{n}}, g_{\mathrm{S}}$, and $\mathrm{E}$ compared with the other three cultivars, whereas 'RADrazz' had greater $\mathrm{P}_{\mathrm{n}}, g_{\mathrm{S}}$, and $\mathrm{E}$ than the other three cultivars (Fig. 2). During the dry down, as SMC decreased, the instantaneous leaf WUE for the four cultivars increased quadratically (Fig. 3). As SMC decreased from $20 \%$ to $10 \%$, WUE increased more rapidly in 'RADrazz' than the other three cultivars (Fig. 3).

Water deficit can affect plants in different ways such as inducing stomatal closure, thus reducing transpiration rates and photosynthesis and, ultimately, inhibiting growth and performance (Yordanov et al., 2003). There were gas exchange differences among cultivars in response to decreased SMC, including higher rates of gas exchange for 'RADrazz'. Decreased gas exchange rates indicate stomatal

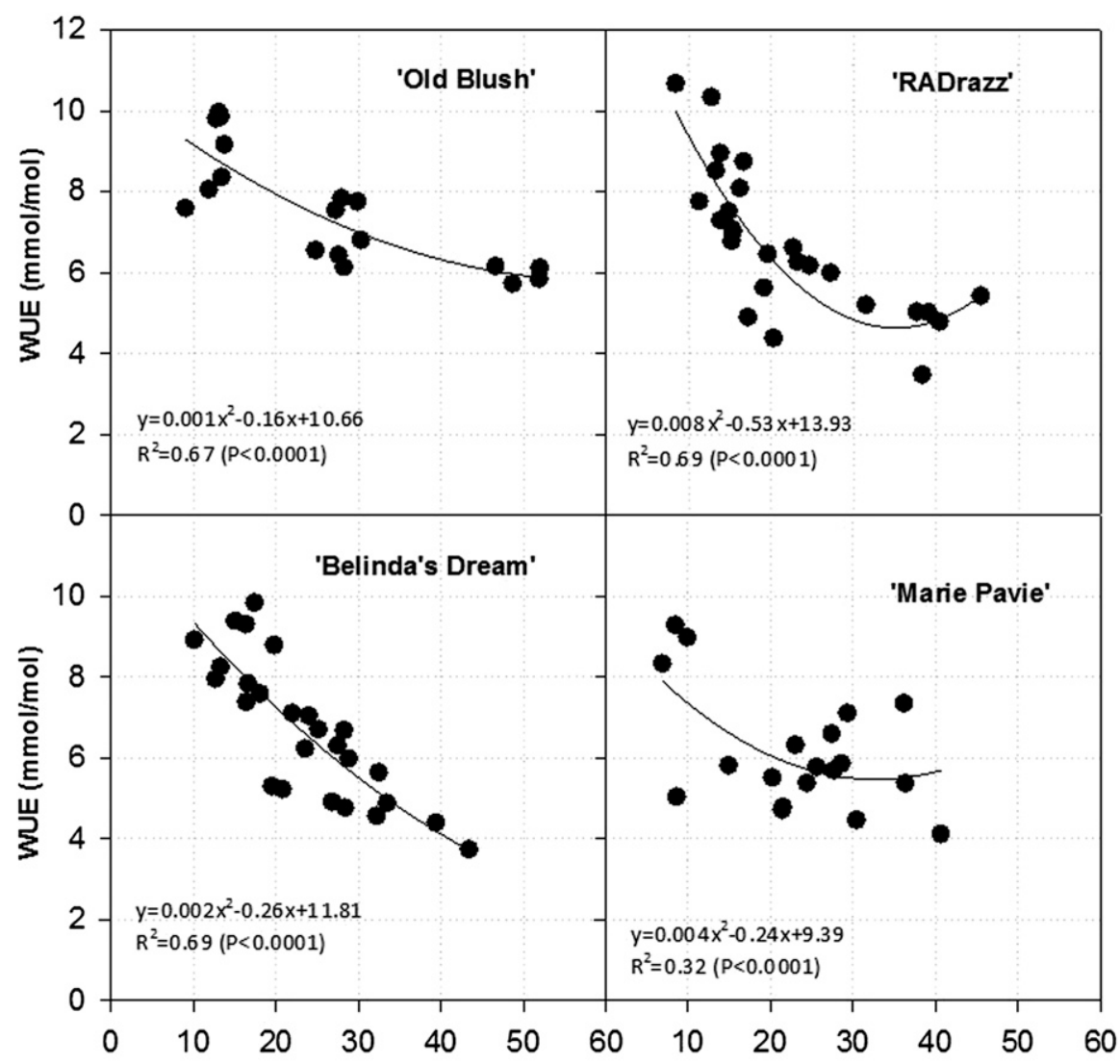

Substrate Moisture Content (\%)

Fig. 3. Relationship between leaf water use efficiency (WUE) and the substrate moisture content (SMC) for four rose (Rosa $\times$ hybrid L.) cultivars, Old Blush, RADrazz, Belinda's Dream, and Marie Pavie, measured during dry down.

closure under low SMC, which is one of the primary defense mechanisms protecting plants from desiccation (Chaves, 1991). Maintaining high gas exchange rates at low $\mathrm{SMC}$ is important in regulating $\mathrm{CO}_{2}$ uptake and water loss from plants. In 'bonfire' salvia (Salvia splendens Sellow), Eakes et al. (1991) reported that E decreased as a result of lower $g_{\mathrm{S}}$ in plants under drought stress, which could account for reduced water loss. In a study on four bedding plants, Nemali and van Iersel (2008) found that $P_{n}$ and $g_{\mathrm{S}}$ decreased at lower SMC. On the days after re-watering, $\mathrm{P}_{\mathrm{n}}, g_{\mathrm{S}}$, and $\mathrm{E}$ were low in all cultivars (Fig. 2), because gas exchange rates took days to recover from drought stress. Jones (1983) also reported that stomata may take days to recover as plants rehydrate after drought stress, and the duration and severity of stress affect the time for recovery.

The physiological parameter of crop WUE is important to describe the relationship between plant water use and dry matter production. With increased WUE, there is a greater biomass production per amount of water transpired and less amount of water needed for growth and development (Nemali and van Iersel, 2008). In several studies (Araus et al., 2002; McKay et al., 2003), it has been reasoned that plants having high
WUE at low $g_{\mathrm{S}}$ in response to drought stress are more drought-resistant. In a study on clover (Trifolium alexandrinum L.), increased instantaneous WUE resulting from lowered water loss was observed in plants under drought stress, which was induced by decreased transpiration rate and leaf area (Lazaridou and Koutroubas, 2004). In our study, high leaf WUE under drought stress was observed in all four cultivars (Fig. 3).

Leaf water potential. During the dry down, midday $\psi$ at SMC between $20 \%$ and $35 \%$ was similar among all cultivars (Fig. 4). At SMC above $35 \%$ or below $10 \%$, midday $\psi$ was more negative in 'Old Blush' when compared with those of the other three cultivars (Fig. 4). These results may have been the result of an infestation of powdery mildew in 'Old Blush' that occurred 2 weeks after treatment initiation. The humidity was very high $(70 \%)$ compared with the first 2 weeks of the experiment (Fig. 1), and 'Old Blush' is susceptible to this disease. The midday $\psi$ was less negative in 'Marie Pavie' than the other three cultivars at SMC less than $10 \%$ (Fig. 4).

Leaf $\psi$ is an important parameter to indicate the level of plant water stress, and water availability to roots could be limited by low $\psi$. Niu and Rodriguez (2009) reported 


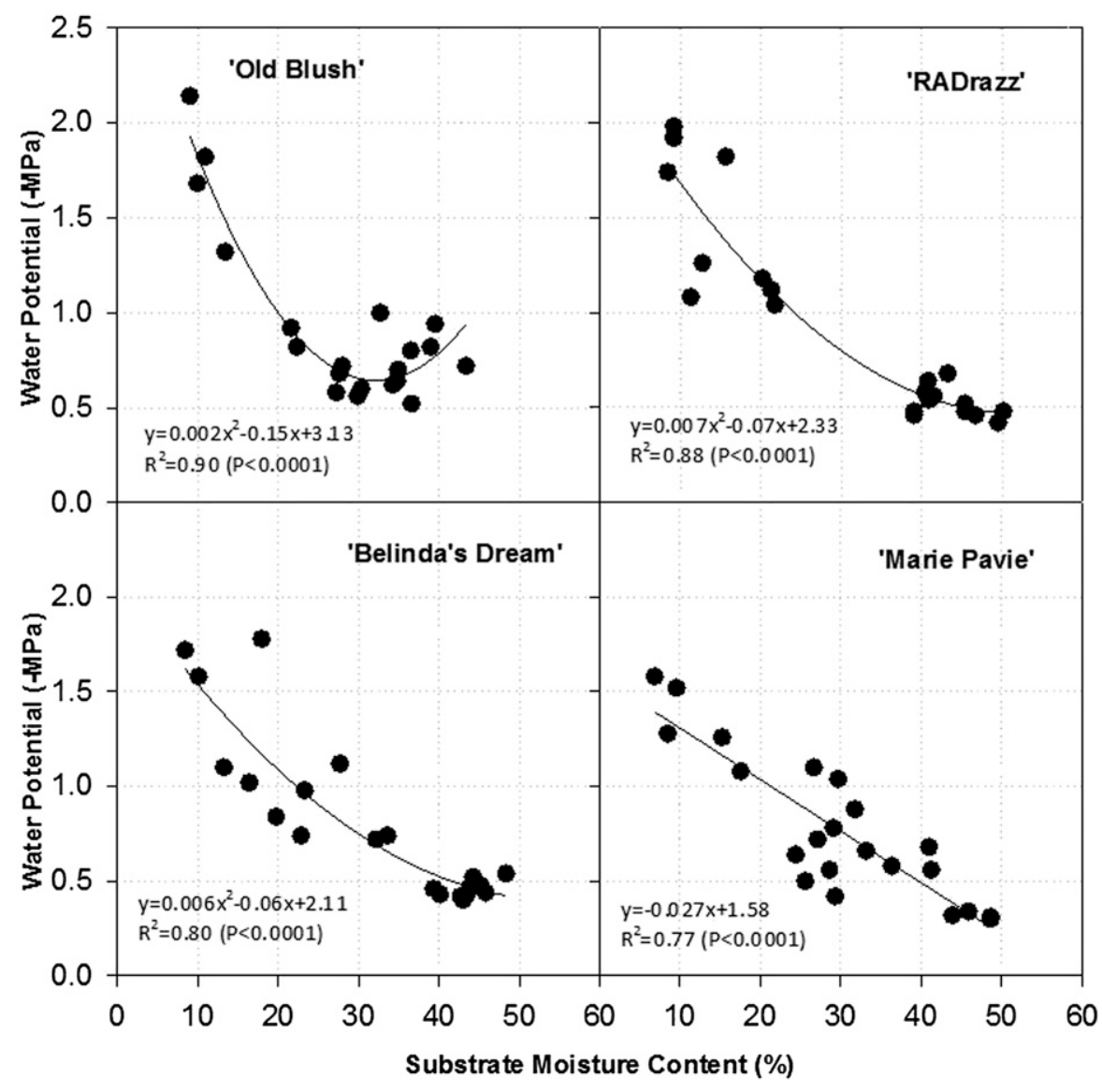

Fig. 4. Relationship between midday leaf water potential $(\psi)$ and the substrate moisture content (SMC) for four rose (Rosa ×hybrid L.) cultivars, Old Blush, RADrazz, Belinda's Dream, and Marie Pavie, measured during dry down.

that predawn $\psi$ decreased rapidly when SMC decreased to a critical value $(\approx 20 \%)$ in R. ×hybrida 'Dr. Huey', R. ×fortuniana, R. multiflora, and $R$. odorata with the most negative $\psi$ in $R$. odorata. In the present study, midday $\psi$ decreased rapidly at SMC less than $20 \%$ in 'Old Blush' and 'RADrazz' (Fig. 4). Based on the present results and those reported in the literature (Niu et al., 2007, 2008; Niu and Rodriguez, 2009), 20\% SMC may be the critical threshold to cause steep declines in leaf $\psi$ in many ornamental plants. Niu and Rodriguez (2009) suggested that frequent measurements of $\psi$ are necessary to identify the critical SMC to detect differences among plants in leaf $\psi$ responses to substrate drying. Decreased $g_{\mathrm{S}}$ resulting from drought stress was reported to aid in maintaining midday leaf $\psi$ in seedlings of tropical rainforest species (Bonal and Guehl, 2001). Plant drought avoidance is related to maintenance of high tissue water potential under water stress conditions to reduce water loss from plants (Stoddard et al., 2006), which can maximize soil moisture use, resulting in lower WUE (Blum, 2005). At low SMC, 'Marie Pavie' had lower gas exchange rates $\left(\mathrm{P}_{\mathrm{n}}, g_{\mathrm{S}}, \mathrm{E}\right.$, and WUE) compared with the other three cultivars; however, midday leaf $\psi$ was relatively higher, which may be explained as drought avoidance to reduce water loss.

\section{Conclusions}

In all four rose cultivars investigated, growth was reduced in drought-treated plants compared with well-irrigated plants but the reduction in 'RADrazz' was the least among the four cultivars. In response to decreasing $\mathrm{SMC}, \mathrm{P}_{\mathrm{n}}, g_{\mathrm{S}}, \mathrm{E}$, and midday $\psi$ decreased, whereas leaf WUE increased in all cultivars. The differences in the physiological responses to drying substrate among the cultivars resulted in their growth differences. 'RADrazz' was more drought-tolerant, followed by 'Old Blush' and 'Belinda's Dream', with its higher $\mathrm{P}_{\mathrm{n}}, g_{\mathrm{S}}, \mathrm{E}$, and leaf WUE at SMC between $10 \%$ and $20 \%$ and smaller growth reduction compared with the other three cultivars. 'Marie Pavie' had the greatest reduction in flower number and lowest gas exchange rates under water deficit conditions, and it was the least drought-tolerant among the cultivars investigated. Further research is needed to investigate the differences in recovery ability of gas exchange rates from drought stress among these cultivars.

\section{Literature Cited}

Aggie Horticulture. 2012. Texas AgriLife Extension Service. Earth-Kind Roses. 31 May 2012. $<\mathrm{http}$ ://aggie-horticulture.tamu.edu/earthkind/ roses/about.html>.
Araus, J.L., G.A. Slafer, M.P. Reynolds, and C. Royo. 2002. Plant breeding and drought in C3 cereals: What should we breed for? Ann. Bot. (Lond.) 89:925-940.

Blum, A. 1996. Crop responses to drought and the interpretation of adaptation. Plant Growth Regulat. 20:135-148.

Blum, A. 2005. Drought resistance, water-use efficiency, and yield potential-Are they compatible, dissonant, or mutually exclusive? Aust. J. Agr. Res. 56:1159-1168.

Bonal, D. and J.M. Guehl. 2001. Contrasting patterns of leaf water potential and gas exchange responses in seedlings of tropical rain forest species. Funct. Ecol. 15:440496.

Bsoul, E., R.S. Hilaire, and D.M. VanLeeuwen. 2006. Bigtooth maples exposed to asynchronous cyclic irrigation show provenance differences in drought adaptation mechanisms. J. Amer. Soc. Hort. Sci. 131:459-468.

Chaves, M.M. 1991. Effects of water deficits on carbon assimilation. J. Expt. Bot. 42:116.

DeLucia, E.H., and S.A. Heckathorn. 1989. The effect of soil drought on water-use efficiency in a contrasting Great Basin desert and Sierran montane species. Plant Cell Environ. 12:935940 .

Eakes, D.J., R.D. Wright, and J.R. Seiler. 1991. Moisture stress conditioning effects on Salvia splendens 'Bonfire'. Amer. Soc. Hort. Sci. 116: 716-719.

Egilla, J.N., F.T. Davies, and T.W. Boutton. 2005. Drought stress influences leaf water content, photosynthesis, and water-use efficiency of Hibiscus rosa-sinensis at three potassium concentrations. Photosynthetica 43: 135-140.

Henderson, J.C., F.T. Davies, and H.B. Pemberton. 1991. Landscape rose response to low moisture levels and a hydrophilic gel. Sci. Hort. 46:129135.

Hsiao, T.C. 1973. Plant responses to water stress. Annu. Rev. Plant Physiol. 24:519-570.

Jones, H.G 1983. Plants and microclimate: A quantitative approach to environmental plant physiology. Cambridge Univ. Press, Oxford, UK.

Kingeman, W.E., M.W. van Iersel, J.G. Kang, R.M. Auge, J.L. Moore, and P.C. Flanagan. 2005. Whole-plant gas exchange measurements of mycorrhizal 'Iceberg' roses exposed to cyclic drought. Crop Prot. 24:309-317.

Lazaridou, M. and S.D. Koutroubas. 2004. Drought effect on water use efficiency of berseem clover at various growth stages. New directions for a diverse planet. Proc. of the $4^{\text {th }}$ International Crop Science Congress, Brisbane, Australia, 26 Sept. to 1 Oct. 2004. <http:// cropscience.org.au>

Lea-Cox, J.D. and D.S. Ross. 2001. A review of the federal clean water act and the Maryland water quality improvement act: The rationale for developing a water and nutrient planning process for container nursery and greenhouse operations. J. Environ. Hort. 19: 226-229.

McKay, J.K., J.H. Richards, and T. MitchellOlds. 2003. Genetics of drought adaptation in Arabidopsis thaliana. I. Pleiotropy contributes to genetic correlations among ecological traits. Mol. Ecol. 12:1137-1151.

Nemali, K.S. and M.W. van Iersel. 2008. Physiological responses to different substrate water contents: Screening for high water-use efficiency in bedding plants. J. Amer. Soc. Hort. 133:333-340. 
Nicolas, E., T. Ferrandez, J.S. Rubio, J.J. Alarcon, and M.J. Sanchez-Blanco. 2008. Annual water status, development, and flowering patterns for Rosmarinus officinalis plants under different irrigation conditions. HortScience 43:15801585.

Niu, G. and D.S. Rodriguez. 2009. Growth and physiological responses of four rose rootstocks to drought stress. J. Amer. Soc. Hort. Sci. 134: 202-209.

Niu, G., D.S. Rodriguez, R. Cabrera, C. McKenney, and W. Mackay. 2006. Determining water use and crop coefficients of five woody landscape plants. J. Environ. Hort. 24:160-165.

Niu, G., D.S. Rodriguez, and W. Mackay. 2008. Growth and physiological responses to drought stress in four oleander clones. J. Amer. Soc. HortScience 133:188-196.

Niu, G., D.S. Rodriguez, L. Rodriguez, and W. Mackay. 2007. Effect of water stress on growth and flower yield of Big Bend bluebonnet. HortTechnology 17:557-560.

Stoddard, F.L., C. Balko, W. Erskine, H.R. Khan, W. Link, and A. Sarker. 2006. Screening techniques and sources of resistance to abiotic stresses in cool-season food legumes. Euphytica 147:167-186.

Williams, M.H., E. Rosenqvist, and M. Buchhave. 1999. Response of potted miniature roses (Rosa $\times$ hybrida) to reduced water availability during production. J. Hort. Sci. Biotechnol. 74: 301-308.

Yordanov, I., V. Velikova, and T. Tsonev. 2003. Plant responses to drought and stress tolerance. Bulg. J. Plant Physiol. 39:187206. 